V. Starova, PhD,

D. Khomenko, PhD, dkhomenko@ukr.net,

R. Doroshchuk, PhD,

R. Lampeka, Dr. Sci.

Taras Shevchenko National University of Kyiv, Kyiv, Ukraine

\title{
3-(2-PYRIDIL)-5-(2-HYDROXYPHENYL)-1,2,4-TRIAZOL AS A REAGENT FOR FLUORIMETRIC DETERMINATION OF MICRO-AMOUNTS OF ZINC
}

The development of new fluorescent reagents for determination of trace amounts of zinc in biological samples is an actual issue. Efficient reagents should characterized by high hydrophobicity, low sensitivity to media acidity and intense fluorescence in the long-wavelength region of the spectrum. Therefore, the using of a rigid $\pi$-conjugated molecule of 3-(2-pyridyl)-5-(2-hydroxyphenyl)-1,2,4-triazole as a fluorescent probe for the determination of zinc micro-quantities in biological samples is considered as a rational choice.

3-(2-pyridyl)-5-(2-hydroxyphenyl)-1,2,4-triazole is a highly hydrophobic ligand (log $P=3.0 \pm 0.1)$. Dissociation of the protonated nitrogen atom in the pyridine cycle of the ligand occurs at $\mathrm{pH}=4, \mathrm{pK} \mathrm{K}_{\mathrm{a}}=3.98 \pm 0.05$. The $\mathrm{pK} \mathrm{K}_{\mathrm{a} 2}$ value is equal to $8.74 \pm 0.03$ and corresponds to the dissociation of the $\mathrm{N}-\mathrm{H}$ group of the triazole fragment. The absorption spectrum of the ligand solution in DMSO is characterized by two bands with maximum at $272 \mathrm{~nm}$ and $320 \mathrm{~nm}$ due to intraligand $\pi-\Pi^{*}$ transitions. The values of the molar absorption coefficient for these bands are $1.18 \cdot 10^{4} \mathrm{I} \cdot \mathrm{mol}^{-1} \cdot \mathrm{cm}^{-1}$ and $1.36 \cdot 10^{4} \mathrm{I} \cdot \mathrm{mol}^{-1} \cdot \mathrm{cm}^{-1}, \mathrm{respectively}$. Two bands at $402 \mathrm{~nm}$ and $535 \mathrm{~nm}$ are also observed on the fluorescence spectra of the ligand. The high fluorescence intensity in the long-wavelength region of the spectrum indicates the promising use of this ligand as an analytical reagent at a creation of new fluoresce techniques.

3-(2-pyridyl)-5-(2-hydroxyphenyl)-1,2,4-triazole as chelating ligand can form two complex compounds in DMSO solution with composition ML and $M L_{2}$. Complex formation is accompanied by the appearance of a third absorption band in the visible regions of the spectrum at $440 \mathrm{~nm}$ $\left(\varepsilon^{440} \approx 6,5 \cdot 10^{3} \mathrm{I} \cdot \mathrm{mol}^{-1} \cdot \mathrm{cm}^{-1}\right)$ due to $L M C T$ transitions. In addition, the complex formation leads to fluorescence quenching.

Developed fluorescent techniques for determination of zinc quantities in a sample of hair and in a tablet of vitamins "Duovit" are characterized by satisfactory precision and accuracy. The range of zinc concentrations determining in the hair sample is $71-286 \mu g / g, S_{r}=0,033(n=3, P=0.95)$. The zinc content that was found in the "Duovit" tablet is well correlated with the declared content. This indicates the good selectivity of ligand in relation to the accompanying microelements.

Keywords: 1,2,4-triazole derivatives, fluorescence, zinc determination.

УДК 543.34: 543.552

DOI: https://doi.org/10.17721/1728-2209.2019.1(56).2

Н. Смик, канд. хім. наук, nsmyk@chem.univ.kiev.ua, Б. Копаниця, студ.,

\section{МОДИФІКОВАНИЙ ЕЛЕКТРОД ДЛЯ ВОЛЬТАМПЕРОМЕТРИЧНОГО ВИЗНАЧЕННЯ NO $_{3}^{-}$ В СОЛОНИХ ВОДАХ}

Запропоновано сенсорний елемент на основі модифікованого скловуглецевого електрода для визначення нітратів у водах із високою солоністю. Оптимізовано умови модифікування електрода шляхом електроосадження на його поверхню міді. Методом ииклічної вольтамперометрії підтверджено, що електроосаджена мідь каталізує реакцію відновлення нітрату, імовірно, до нітриту. Показано, що струм відновлення нітрату зростає зі збільшенням вмісту хлориду в розчині й досягає максимального значення в інтервалі $(2-3,5) \cdot 10^{-1}$ моль/л $\mathrm{Cl}$. Вплив кислотності незначний в інтервалі рН 3,5-6,0. Було оптимізовано умови прямого визначення нітрату в нейтральному середовищі за присутності 2.103-кратних надлишків хлориду. Сенсор було застосовано при аналізі імітата морської води без попередньої пробопідготовки. Отримані дані добре корелюють з результатами, що отримані потенціометричним методом зі стандартним іон-селективним електродом після осадження хлоридів.

Ключові слова: вольтамперометрія, скловуглецевий електрод, нітрат, морська вода.

Вступ. Нітроген - один з найбільш поширених елементів у природі, необхідний для розвитку всіх живих організмів. В акваріумних водах основним джерелом нітрогену $є$ аміак, що потрапляє туди разом із продуктами життєдіяльності риб. У процесі нітрифікації аміак перетворюється на нітрат-іони. Більшість водних організмів здатна виживати навіть за дуже значних показників вмісту нітратів, але концентрації вищі, ніж 0,2 мг/л, призводять до захворювань риб і евтрофрікації та цвітіння акваріумів. Отже, вміст $\mathrm{NO}_{3}^{-} €$ важливим індикатором якості води. Зазвичай низькі концентрації $\mathrm{NO}_{3}{ }^{-}$у морській воді потребують застосування чутливих методів аналізу, а відсутність способів тривалого зберігання проб без зміни співвідношення $\mathrm{NO}_{3}{ }^{-} / \mathrm{NO}_{2}{ }^{-}$вимагає визначення безпосередньо на місці відбору проб. Необхідність регулярного контролю складу води в акваріумах обумовлює застосування швидких та дешевих методів аналізу.

Одночасне визначення $\mathrm{NO}_{3}{ }^{-}$та $\mathrm{NO}_{2}^{-}$потребує значних зусиль. Існує кілька основних підходів до розв'язання цієї проблеми $[1,2]$. Найбільш чутливі методи одночасного визначення вмісту $\mathrm{NO}_{2}{ }^{-}$та $\mathrm{NO}_{3}{ }^{-}-$іонна хроматографія (IX) та капілярний зонний електрофорез [3, 4] складні в реалізації, дороговартісні, потребують високої фрахової підготовки персоналу та складної пробопідготовки. Більш прості та широко вживані методи - фотометричний та люмінесцентний - при включенні в сучасні проточно-інжекційні системи $[5,6]$ дозволяють із достатньою чутливістю визначати вміст $\mathrm{NO}_{2}^{-}$(після переведення в азобарвник за реакцією азосполучення 3 ароматичним аміном), визначення $\mathrm{NO}_{3}^{-}$можливе лише після відновлення до нітриту. Ці методи потребують тривалої пробопідготовки в умовах стаціонарної лабораторії та не можуть бути застосовані для аналізу на місці відбору проб. Пряме спектрофотометричне визначення нітрату за власним поглинанням в УФ-діапазоні ( 200 нм) можливе лише для незабарвлених проб за відсутності розчинених органічних речовин [7]. Результати застосування ряду спеціальних тест-систем, що випускаються промисловістю, не завжди задовольняють вимоги за чутливістю та вибірковістю при застосуванні у морській воді високої солоності $[8,9]$. Потенціометрія із застосуванням комерційних іон-селективних електродів (ICE), вибіркових до $\mathrm{NO}_{3}{ }^{-}$, потребує спеціальної підготовки проб води з високою солоністю й може проводитися лише методом добавок $[10,11]$. Тому пряма вольтамперометрія видається перспективним методом для розв'язання поставленого завдання.

Значна частина відомих вольтамперометричних методик визначення нітрату базується на його здатності відновлюватись на робочому електроді до нітрит- [12], амоній-іонів [13] та нітрогену. Оскільки процеси відновлення необоротні, то необхідно забезпечити наявність 
на поверхні робочого електрода великої кількості каталітично активних центрів. Як матеріал для виготовлення робочих електродів застосовують важкі метали [14, 15] та різні вуглецеві матеріали [16, 17]. Серед металічних найбільш перспективними виявилися мідні, кадмієві та срібні електроди. Але поверхня масивних, зокрема мідних, електродів занадто швидко пасивується [18]. Для подолання цього недоліку запропоновано ряд способів попередньої активації поверхні, зокрема шляхом послідовного розчинення/осадження міді на поверхні масивного мідного електрода [12], електроосадження міді на платиновому wall-jet електроді [19] та кадмію на золотому дисковому електроді [20]. Схожого ефекту вдалося досягти також при застосуванні електродів 3 вуглецевих матеріалів, модифрікованих металами, які здатні каталізувати процес відновлення нітрату, зокрема срібла на платиновому носії [21], іридію на електроді 3 вуглецевих волокон [22], міді та кадмію на піролізному графіті [23] та міді на поверхні вугільного електрода капілярної будови [24]

В усіх випадках отримання активованої поверхні потребувало значного часу, складної пробопідготовки, видалення кисню з розчинів та/або не забезпечувало вибірковості, необхідної для проведення аналізу солоних вод.

Мета роботи - обрати матеріал та конструкцію електрода, здешевити та оптимізувати спосіб його модифікації з метою виготовлення чутливого елемента для визначення нітратів у солоних водах вольтамперометричним методом 3 мінімальною пробопідготовкою та без шкоди для довкілля.

Матеріали і обладнання. У роботі використовували бідистильовану воду, натрієві солі нітрат, нітрит, сульфрат та перхлорат; купрум (II) сульфат; хлоридну та сульфатну кислоти; калій гідроксид та хлорид. Реагенти кваліфікації х.ч. використовували без додаткового очищення. Вихідні (0,1 моль/л) розчини готували розчиненням точної наважки у воді. Розбавлені розчини готували в день проведення досліджень. Вихідний розчин аргентум сульфату готували розчиненням точної наважки у сульфатній кислоті та наступним розбавленням водою до необхідного об'єму згідно з рекомендаціями [25]. Оксалатний буферний розчин (pH 5,2) готували відповідно до методики [25]. Перевірку запропонованої методики проводили з використанням розчину природної морської солі (імітат морської води). Для його виготовлення 0,2399 г зразка "Сіль морська для ванн Наталі-ефект натуральна" виробництва "Гармонія ПП" (Україна, Каховка) вносили в мірну колбу на 100,0 мл, розчиняли і доводили водою до необхідного об'єму. Через добу розчин фільтрували для видалення механічних забруднень.

Зважування проводили на електронних аналітичних терезах KERN and Sohn GmbH (Німеччина).

Потенціометричні дослідження проводили за допомогою потенціометра "Эконикс-Эксперт". Як електрод порівняння використовували 3,5 моль/л хлоридсрібний електрод з подвійним сольовим містком "ЭСр-10101". Як індикаторний використовували іон-селективний електрод зі скляною ("ЭСЛ-15-11", контроль кислотності) або плівковою ("ЭЛИС-121 $\mathrm{NO}_{3} "$, вимірювання $\mathrm{pNO}_{3}$ ) мембранами. Вольтамперометричні (ВА) дослідження проводили за допомогою потенціостата IPC-ProMF із програмою керування "IPC-Pro 2000". Виміри проводили в триелектродній комірці зі стандартним хлоридсрібним електродом порівняння, платиновим струмовідводом та робочим скловуглецевим електродом (CByE, площа робочої поверхні 3,14 мм², виробництва ООО "Эконикс-Эксперт"). СВуЕ перед роботою полірували спеціальною пастою протягом двох хвилин, після чого промивали його поверхню сульфатною кислотою, бідистильованою водою та етиловим спиртом і висушували фільтрувальним папером.

Методи та об'єкти досліджень. Серед робочих електродів (PE) на основі вуглецевих матеріалів привертає увагу скловуглецевий електрод [26]. Він має незначну пористість, яка залежить від температури його виготовлення, стійкий до дії лугів, кислот, окиснювачів, руйнується лише в суміші концентрованих сульфатної та нітратної кислот. Перенапруга виділення кисню і водню на CBуE з водних розчинів досить висока, і робоча область потенціалів дозволяє проводити анодні/катодні процеси в області потенціалів від $+0,8$ до -1,4 В. Адсорбція кисню і водню незначна. Запропоновано низку прийомів для покращення перебігу редокс-процесів на CВуЕ. Основними є механічна $[27,28]$ та електрохімічна активація [29] поверхні й хімічне модифрікування [30]. Кожен із цих способів сприяє створенню на поверхні електрода активних центрів, що будуть полегшувати (зменшувати) перенапругу досліджуваного електродного процесу. 3 огляду на оптимальне співвідношення складності методу отримання й ефективності підготовленого електрода оптимальним видається іммобілізація на поверхні електрода нанорозмірних частинок металів, а найпростішим способом їх закріплення є осадження. У представленій роботі активацію поверхні CBуЕ проводили шляхом електроосадження міді.

У літературі описано принаймні два можливі способи застосування модифікованих у такий спосіб електродів. Поверхню РЕ попередньо модифікують в окремому розчині, переносять модифікований електрод у досліджуваний розчин і проводять необхідні вимірювання. Перевагою цього методу $є$ можливість багаторазового використання модифікованого електрода, але нею можна скористатися лише у випадку, коли отриманий шар модифікатора не змінює властивостей в часі та при контакті з атмосферою й досліджуваними розчинами.

Згідно з іншим способом модифікація відбувається безпосередньо під час проведення аналізу. Для реалізації такого on-line-модифікування поверхні PE в програму керування зміною потенціалу в процесі аналізу вводять спеціальну підготовчу стадію - електрод протягом певного часу витримують при потенціалі, оптимальному для утворення шару модифікатора, а до досліджуваного розчину вводять спеціальну речовину, з якої внаслідок адсорбції чи електролітичного осадження утворюється шар модифікатора. Останній спосіб в нашому випадку видається більш доцільним, оскільки згідно з даними літератури активні центри, утворені шляхом електроосадження міді, дуже швидко втрачають чутливість (отруюються).

У представленій роботі шар модифікатора отримували безпосередньо в процесі запису вольтамперограми. Це можливо, оскільки під час катодної розгортки потенціалу PE відновлення міді(II) відбувається раніше за відновлення нітрату.

Для вивчення впливу матеріалу та конструкції робочого електрода, складу розчину й параметрів запису вольтамперограми на процес відновлення нітрату використовували метод циклічної вольтамперометрії (ЦВА). В усіх випадках як аналітичний сигнал обирали пік на вольтамперограмі, висота якого зростає при збільшенні концентрації нітрату в розчині.

Потенціал змінювали в інтервалі від -50 до -1400 мВ. Як оптимальний для СВуЕ був обраний діапазон розгортки потенціалів від -200 мВ до -1400 мВ. У більш позитивній області потенціалів шар електровідновленої міді, імовірно, втрачає оптимальну морфологію, і каталітична активність його знижується, унаслідок чого аналітичний сигнал нітрату істотно зменшується. За більш від'ємних значень потенціалів може руйнуватися матеріал електрода. 
Швидкість зміни потенціалу становила 10 мВ/с у всіх дослідах, окрім вивчення її впливу на аналітичний сигнал.

Потенціометричне визначення концентрації нітратіонів в імітаті морської води проводили з використанням методу добавок після осадження основної маси хлориду розчином арґентум сульфату за методикою [10]. Для цього до 10,0 мл досліджуваного розчину, що імітує морську воду, додавали 1,0 мл оксалатного буферу, 1,0 мл стандартного розчину $\mathrm{Ag}_{2} \mathrm{SO}_{4}$ та 2,0 мл води. Розчин ретельно перемішували і вимірювали потенціал ICE за відсутності та після внесення добавок від 0,1 до 0,4 мл стандартного 0,1 моль/л розчину $\mathrm{KNO}_{3}$. Для розрахунку вмісту $\mathrm{NO}_{3}^{-}$в імітаті морської води розв'язували систему рівнянь:

$$
E_{x}=K+s \times \lg C_{x},
$$

де $E_{x}$ - потенціал індикаторного електрода до та після внесення добавки, $C_{x}$ - концентрація розчину до та після внесення добавки, $K$ та $s-$ константа та крутизна електродної функції ICE. Величини $K$ та $s$ було визначено в окремому досліді.

Результати досліджень та їх обговорення. Про ефективність запропонованого способу модифікації CBуE для покращення умов визначення нітрату вольтамперометричним (BA) методом свідчить поява чіткого

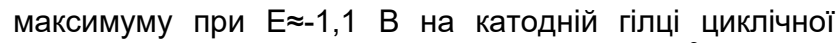
вольтамперограми розчинів нітрату (5,610-3 моль/л) лише за присутності $\mathrm{Cu}^{2+}$ в розчині (рис. 1, крива 2). Висота цього максимуму збільшується при збільшенні вмісту нітрату (рис. 2). Тому цей сигнал було обрано як аналітичний і наступні дослідження проводились 3 метою оптимізації умов його отримання у зручній для подальшої обробки формі.У ряді попередніх досліджень [13, 18] було показано, що на мідному електроді в сульфатнокислому середовищі кінцевим продуктом відновлення нітрату $\epsilon$ іони амонію: $\mathrm{NO}_{3}{ }^{-}+8 \mathrm{e}+10 \mathrm{H}^{+} \rightarrow \mathrm{NH}_{4}{ }^{+}+3 \mathrm{H}_{2} \mathrm{O}$. У нейтральному середовищі відновлення відбувається, імовірно, до нітриту [31, 32]: $\mathrm{NO}_{3}^{-}+2 \mathrm{e}+\mathrm{H}_{2} \mathrm{O} \rightarrow \mathrm{NO}_{2}^{-}+$ $2 \mathrm{OH}^{-}$. Ми вважаємо, що отриманий аналітичний сигнал пояснюється перебігом одного з цих процесів, але детальне дослідження механізму електровідновлення нітрату на модифікованому CBуE не було метою представленої роботи. Обидва процеси необоротні й дуже чутливі як до матеріалу і стану поверхні електрода, так і до складу фронового електроліту. Тому нами було досліджено вплив діапазону та швидкості розгортки потенціалу, концентрації купруму(II), pH та аніонного складу фонового електроліту на форму і величину максимуму відновлення нітрату.

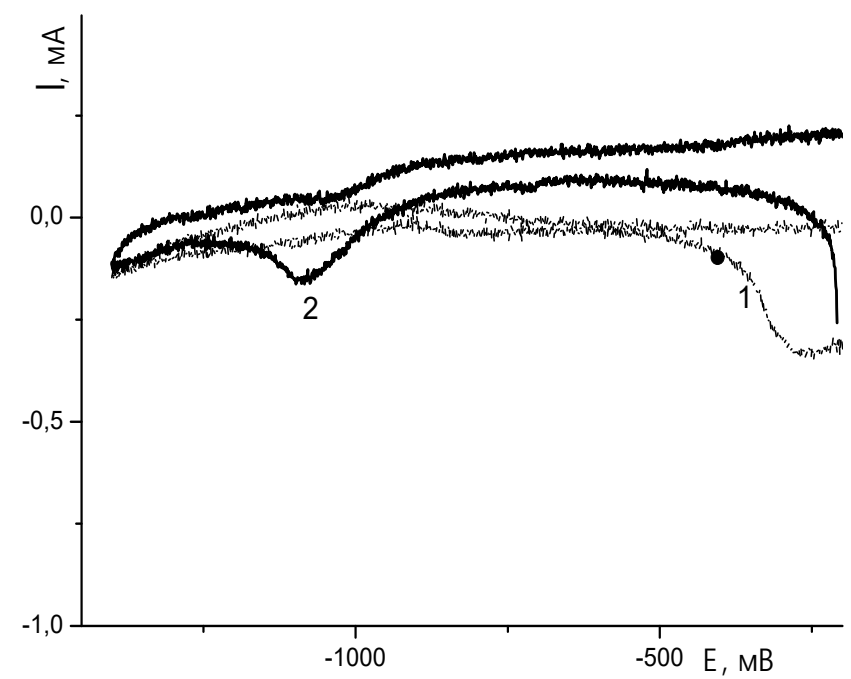

Рис. 1. Циклічні вольтамперограми розчинів $\mathrm{KNO}_{3}$ на скловуглецевому робочому електроді за відсутності (1) та у присутності (2) $\mathrm{CuSO}_{4}$. Концентрації (моль/л): 5,6-10-3 $\mathrm{KNO}_{3}^{-}, 0,2 \mathrm{CuSO}_{4}$. Фоновий електроліт $\mathrm{H}_{2} \mathrm{SO}_{4}\left(1 \cdot 10^{-4}\right.$ моль/л)

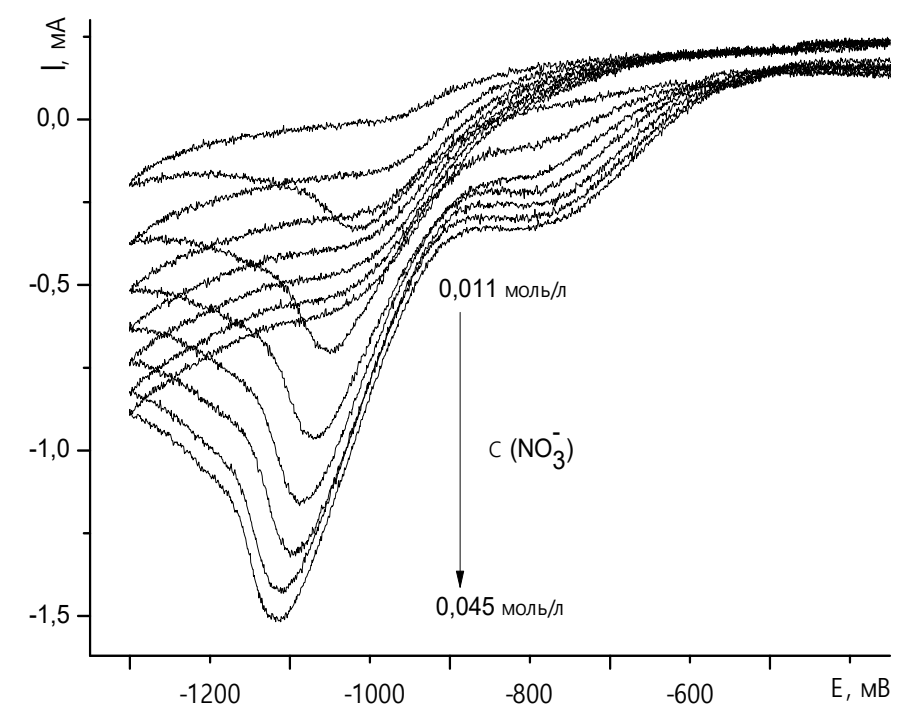

Рис. 2. Циклічні вольтамперограми розчинів $\mathrm{KNO}_{3}$ на скловуглецевому робочому електроді у присутності $\mathrm{CuSO}_{4}$

(0,2 моль/л). Фоновий електроліт KCl (0,02 моль/л, pH 5,6) 
Установлено, що нітрат не відновлюється на СВуЕ 3 3,0·10-2 моль/л розчину (фон $1,0 \cdot 10^{-1}$ моль/л $\mathrm{Na}_{2} \mathrm{SO}_{4}$, $\mathrm{pH} 4,7 \pm 0,1)$ за концентрацій $\mathrm{Cu}(\mathrm{II})$ менших ніж 5,0110-4 моль/л. Імовірно, за цих умов активних центрів утворюється занадто мало для отримання необхідної каталітичної активності поверхні електрода.

В інтервалі концентрацій купруму(II) від 5,0·10-4 до $5 \cdot 10^{-3}$ моль/л аналітичний сигнал, що визначається відновленням нітрату, збільшується і залишається приблизно сталим до його вмісту (4-5)·10-2 моль/л. При подальшому збільшенні концентрації купрум(II) сульфату вигляд кривої спотворюється, пік розширюється, а максимум зсувається в катодну ділянку, а при концентрації $\mathrm{CuSO}_{4} \geq 2 \cdot 10^{-2}$ моль/л на поверхні електрода утворюється видимий оком шар металічної міді. Це призводить до негативних наслідків - по-перше, утворений шар губчастий унаслідок одночасного виділення газоподібного водню і тому мідь фізично не утримується на поверхні; по-друге, електрод, щільно вкритий шаром міді, починає поводитися як об'ємний мідний електрод, зокрема втрачає каталітичну активність. Отже, оптимальною концентрацією $\mathrm{CuSO}_{4}$ було обрано $2 \cdot 10^{-1}$ моль/л, подальші дослідження проводили саме за такого його вмісту.

Оптимальна область рН обмежена умовами аналізу. 3 одного боку, середовище має не бути занадто кислим, оскільки вже при $\mathrm{pH}<3,5$ на робочому електроді інтенсивно відбувається реакція виділення водню. Пік на вольтамперограмі, що відповідає цьому процесу, дуже широкий і "поглинає" можливий пік відновлення нітрату. 3 іншого боку, середовище не може бути дуже лужним, оскільки вже при $\mathrm{pH}>6$ починають утворюватися спо- луки складу $\mathrm{Cu}(\mathrm{OH})^{+}$та осад купрум(II) гідроксиду, що заважають утворенню активних центрів на поверхні електрода. Установлено, що у вибраному діапазоні $\mathrm{pH}$ не впливає на висоту, форму та положення максимуму на вольтамперограмі відновлення нітрату. 3 огляду на те, що $\mathrm{pH}$ морської води $\approx 5,5$, подальші вимірювання проводили за $\mathrm{pH} \mathrm{5,6 \pm 0,1} \mathrm{для} \mathrm{спрощення} \mathrm{пробопідготовки}$ при подальшому аналізі реальних зразків.

Фоновий електроліт необхідний, у першу чергу, для підтримання і підвищення електропровідності розчину. Однак його компоненти можуть входити до складу подвійного електричного шару (ПЕШ) на поверхні електрода та/або утворювати нові сполуки з досліджуваною речовиною. Усі ці ефекти іноді призводять до зміни умов перебігу окисно-відновної реакції і, відповідно, зміни характеру аналітичного сигналу. Як основний компонент фонового електроліту нами були випробувані 0,1 моль/л розчини $\mathrm{Na}_{2} \mathrm{SO}_{4}, \mathrm{NaClO}_{4}$ та $\mathrm{KCl}$, оскільки вони не піддаються електроперетворенню у вибраній ділянці потенціалів і $є$ комерційно доступними. Кращі результати було отримано в розчинах, які містили аніони сульфат та хлорид. В обох випадках спостерігався сигнал при $\mathrm{E} \approx-1,1 \mathrm{~B}$. Але у хлоридному фоновому розчині пік, що відповідає відновленню нітрату, більш вузький. 3 огляду на це, а також ураховуючи необхідність подальшого застосування методики для аналізу морської води, де присутній величезний надлишок хлорид-іонів, подальші дослідження проводили саме в цьому фоновому електроліті.

Дослідження впливу концентрації хлориду на фрорму ВА кривої відновлення нітрату (рис. 3) показало доволі цікаві результати.

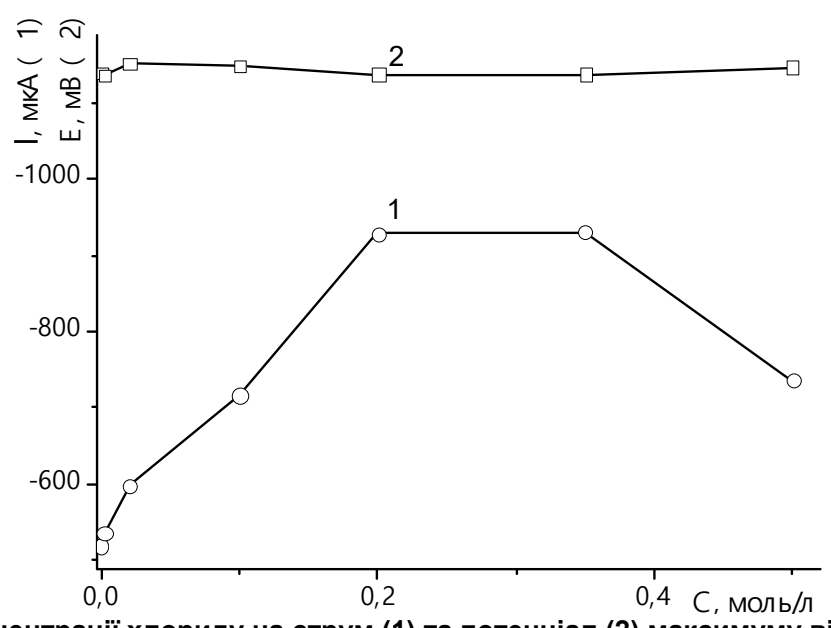

Рис. 3. Вплив концентрації хлориду на струм (1) та потенціал (2) максимуму відновлення нітрату

Видно (рис. 3, крива 1), що в інтервалі концентрацій хлориду від $2 \cdot 10^{-4}$ до (2-3) $10^{-1}$ моль/л аналітичний сигнал збільшується. При цьому пік відновлення нітрату звужується і стає більш симетричним, тобто форма його стає більш зручною для подальшої обробки. Потенціал максимуму в цій області концентрацій практично не змінюється, що може свідчити про сталість умов перебігу електродної реакції. За вищих концентрацій хлориду форма максимуму спотворюється, величина його зменшується. Тому подальші дослідження проводили саме за вмісту $\mathrm{Cl}^{-}$у фооновому електроліті $2 \cdot 10^{-1}$ моль/л.

Схожий, але менш значний вплив на відновлення нітрату справляють також інші галогеніди - йодид та фрторид. Можливо, цей вплив пояснюється їх адсорбцією на поверхню електрода і наступною перебудовою ПЕШ - як у випадку відновлення нітрату на об'ємному мідному електроді [33]. Інше пояснення подібного ефректу збіль- шення аналітичного сигналу при відновленні нітрату в хлоридному середовищі на модифікованому міддю платиновому електроді було наведено в роботі [24]. Було показано, що під час попередньої стадії накопичення міді на платиновому електроді з хлоридних розчинів на поверхні електрода утворюються сполуки, які містять потрійні структури М - $\mathrm{Cl}^{-}-\mathrm{Cu}(\mathrm{II})$, де $\mathrm{M}$ - це $\mathrm{Cu}$ або Pt. Саме вони, як вважають автори [24], і спричинюють зменшення активаційного бар'єру редокс-реакції. Який саме механізм сприяє покращенню аналітичного сигналу нітрату за умов застосування запропонованого в нашій роботі мідь-модифікованого CВуE, нам наразі не зовсім зрозуміло, це потребує проведення подальших ґрунтовних досліджень.

За оптимальних умов проведене визначення добавок нітрату до розчину природної морської солі (для ванн) методом введено-знайдено. Перевірку отриманих результатів здійснено методом потенціометрії із стандартним ICE. 
Результати визначення добавок калій нітрату до імітату морської води

\begin{tabular}{|c|c|c|}
\hline \multirow{2}{*}{ Введено, 10-4 моль/л } & \multicolumn{2}{|c|}{ Знайдено, 10-4 моль/л } \\
\cline { 2 - 3 } & Потенціометричним методом & 3апропонованим методом \\
\hline 7,1 & 7,5 & 7,97 \\
\hline 34,5 & 34,9 & 35,4 \\
\hline 54,1 & 54,6 & 55,1 \\
\hline
\end{tabular}

Результати добре узгоджуються. Значною перевагою запропонованого методу порівняно із потенціометричним $€$ значна економія часу та трудовитрат унаслідок майже повної відсутності пробопідготовки.

Подяка. Автори висловлюють глибоку вдячність асистенту кафедри аналітичної хімії канд. хім. наук Лелюшку С. О. за технічну допомогу в організації експериментальної роботи.

Висновки. Досліджено умови модифікування СВуЕ шляхом електроосадження міді на його поверхню. Оптимізовано умови для вольтамперометричного визначення нітрат-іонів на рівні середнього вмісту у природних водах за присутності $2 \cdot 10^{3}$-кратного надлишку хлорид-іонів. Показано перспективність використання модифікованого електрода як сенсору для прямого визначення нітрат-іонів у морській воді без попередньої пробопідготовки.

Список використаних джерел

1. Moorcroft M. J., Davis J., Compton R. G. Talanta. 2001. 54. 785-803.

2. Alahi Md. E. E., Mukhopadhyay S. C. Sens. Actuators, A. 2018. 280. 210-221.

3. Michalski R., Kurzycal I. Pol. J. Environ. Stud. 2006. 15(1). 5-18.

4. Betta F. D., Vitali L., Fet R., Oliveira Costa A. C. Talanta. 2014. 122. 23-29.

5. Paczosa-Bator B., Cabaj L., Raś M., Baś B., Piech R. Int. J. Electrochem. Sci. 2014. 9. 2816-2823.

6. Chang Z., Zhu Y., Zhang L., Du S. Instrumentation, Measurement, Computer, Communication and Control (IMCCC). 2013 Third International Conference, IEEE2013, Berlin, 2013. 48-52.

7. Swift D. D. Riser S. C. J. Atmos. Ocean. Tech. 2013. 30. 1854-1866.

8. Supelco [Electronic resource]. URL : https://www.sigmaaldrich.com/ catalog/product $/ \mathrm{mm} / 110020$ ?lang=en\&region=UA.

9. CHEMetrics [Electronic resource]. URL : https://www.chemetrics.com/ product-category/test-kits/nitrate/.

10. Ghassemzadeh F., Sherwood J., Geddes M. C., Williams W. D. Int. J. Salt Lake Res. 1997. 6(3). 269-278.

11. Смик Н., Запорожець О., Копаниця Б. Збірник наукових праць VIII Українського з'їзду з електрохімії. Львів, 2018. 249-251.
Smyk N., Zhaporozets O., Kopanitsa B., Proc. VIII Ukr. Congr. on Electrochem. Lviv, 2018. 249-251 (in Ukrainian).

12. Shariar S. M. Hinoue T. Anal Sci. 2010. 26(11). 1173-1179.

13. Burke L. D., O'connel A. M., Sharna R., Buckley C. A. J. Appl. Electrochem. 2006. 36. 919-923.

14. Yunus M. A. M., Mukhopadhyay S. C. IEEE Sens. J. 2011. 11(6). $1440-1447$

15. Lotfi Zadeh Zhad H. R., Lai R. Y. Anal. Chim. Acta. 2015. 892. 153-159.

16. Mahmoudian M. R., Alias Y., Basirun W. J., Mengwoi P., Sheini F. J., Sookhakian M. J. Electroanal. Chem. 2015. 751. 30-36.

17. Shiddiky M. J. A., Won M. S., Shim Y. B. Electrophoresis. 2006. 27(22). 4545-4554

18. Pletcher D., Poorabedi Z. Electrochim. Acta. 1979. 24. 1253-1256.

19. Albery W. J., Borry B. G. D., Jones C. P., Britchard M. J., Svanberg L.

R. Electroanal. Chem. 1985. 188. 257-263.

20. Xing X., Scherson D. A. Anal. Chem. 1987. 59. 962-964.

21. Lebon E., Fau P., Comtat M., Kahn M. L., Sournia-Saquet A., Temple-Boyer

P., Dubreuil B., Behra Ph., Fajerwerg K. Chemosensors. 2018. 50(6). 81-93.

22. De D., Englehardt J. D., Kalu E. E. J. Electrochem. Soc. 2000. 147(11). 4224-4228.

23. Bodini M. E., Sawyer D. T. Anal. Chem. 1977. 49. 485-489.

24. Fogg A. G., Sucllion S. P., Edmonds T. E., Birch B. J. Analyst. 1991. 116. 573-579.

25. Коростелев П. П. Приготовление растворов для химико-аналитических работ. М : Изд-во АН СССР, 1962. 311 с.

Korosteliov P. P. Preparation of solutions for chemical analytical work. Moscow : Publishing house of AS USSR, 1962. $311 \mathrm{p}$

26. Herber R. F. M., Stoeppler M. Trace Element Analysis in Biological Specimens. New York : Elsevier, 1994. 576 p

27. Poon M., McCreery R. L. Anal. Chem. 1986, 58, 2745-2753.

28. Zhang H., Coury L. A. Anal. Chem. 1993. 65. 1552-1558.

29. Braun A. Development and Characterization of Glassy Carbon Electrodes for a Bipolar Electrochemical Double Layer Capacitor. Hamburg : Diplomica $\mathrm{GmbH}, 2002.256$.

30. Zhang X.-I., Wang J.-X., Wang Z., Wang S. Sensors. 2005. 5. 580-593.

31. Krista J., Kopanica M., Novotny L. Electroanalysis. 2000. 12. 199-204.

32. Bhat M. A., Ingole P. P., Chaudhari V. R., Haram S. K. New J. Chem. 2009. 33. 207-210.

33. Solak A. O., Gülser P., Gökm E., Gökmesşe F. Microchim. Acta. 2000. 134. $77-82$

Надійшла до редколегії 18.07.19

Н. Смык, канд. хим. наук, nsmyk@chem.univ.kiev.ua

Б. Копаница, студ.,

Киевский национальный университет имени Тараса Шевченко, Киев, Украина

\section{МОДИФИЦИРОВАННЫЙ ЭЛЕКТРОД ДЛЯ ВОЛЬТАМПЕРОМЕТРИЧЕСКОГО ОПРЕДЕЛЕНИЯ $\mathrm{NO}_{3}$-В СОЛЕНЫХ ВОДАХ}

Предложен сенсорный элемент на основе модифицированного стеклоуглеродного электрода для определения нитратов в водах высокой солености. Оптимизированы условия получения модифицирующего слоя путем электроосаждения меди на поверхность электрода. Методом циклической вольтамперометрии подтверждено, что электроосажденная медь катализирует реакцию восстановления нитрата до нитрита. Показано, что ток восстановления нитрата увеличивается с увеличением концентрации хлорида в растворе и достигает максимума в интервале $(2-3,5) \cdot 10^{-1}$ моль/л. Влияние кислотности на электродную реакцию незначительно в интервале рН 3,5-6,0. Разработана методика прямого определения нитратов в нейтральной среде в присутствии 2.103-кратного избытка хлоридов. Сенсор был применен при анализе имитата морской воды без предварительной пробоподготовки. Полученные результаты коррелируют с результатами анализа потенциометрическим методом.

Ключевые слова: вольтамперометрия, стеклоуглеродный электрод, нитрат, морская вода.

N. Smyk, Ph.D, nsmyk@chem.univ.kiev.ua,

B. Kopanytsa, stud.

Taras Shevchenko National University of Kyiv, Kyiv, Ukraine

\section{MODIFIED ELECTRODE FOR NO${ }_{3}^{-}$DETERMINATION IN SALINE WATERS BY VOLTAMMETRY METHOD}

A certain level of $\mathrm{NO}_{3}^{-}$in water is necessary for the growth of algae. Most aquatic organisms can survive at relatively high nitrate levels, but concentrations higher than $0.2 \mathrm{mg} / \mathrm{l}$ cause fish diseases, eutrophication and algal bloom in aquariums. Thus, it is necessary to monitor the level of nitrates in aquarium water.

When choosing the method of nitrate level analysis that will be used to develop an in-site saltwater monitor system, we should take into account several key factors, such as the threshold concentration and possible inferences, including high levels of $\mathrm{Cl}^{-}$in saltwater. Other desired criteria for the method are the need to get results in real time, low cost of production, and a way to perform the measurements in-site without the need for highly skilled personnel.

The voltammetry was chosen as a method that satisfies our criteria. It is known that nitrate can be reduced quantitatively on a copper electrode. However, the copper electrode becomes poisoned after only a few minutes of use. Previous studies showed that a thin layer of copper deposited on the surface of various commonly used electrodes significantly improve the perfomance of the sensing system. This paper describes the fabrication process of voltammetric sensor and shows the advantage of using a glassy carbon electrode modified with electrodeposited copper layer to measure the concentration of nitrate in sea water. We have found that the modified sensor can be effectively used to catalyze nitrate reduction with a well- 
defined reduction wave with $E=-1.1 \mathrm{~V}$. We performed the cyclic voltammetric (CV) experiments and chose an optimal supporting electrolyte and the optimal conditions for the pretreatment. It was found that the peak current of nitrate increases with the increase of $\mathrm{Cl}$ concentration and is stable in the range (2-3) $10^{-1} \mathrm{~mol} / \mathrm{l}$. The $\mathrm{pH}$ value from 3.5 to 6.0 does not influence the reaction on an electrode.

The developed sensor was used to direct determine of nitrate in artificial seawater without of any sample preparation. Potentiometry with standard procedure of $\mathrm{Cl}^{-}$precipitation was used to validate all the results. The values obtained by both methods were in good agreement with each other.

Key words: voltammetry, glassy carbon electrode, nitrate, sea water.

УДК 541.183:543.4.062:543.41:546.24:546.86

DOI: https://doi.org/10.17721/1728-2209.2019.1(56).3

В. Верба, канд. хім. наук,

О. Запорожець, д-р хім. наук,

І. Кухаренко, студ.,

$\epsilon$. Кульбака, студ.,

Київський національний університет імені Тараса Шевченка, Київ, Україна

\section{СОРБЦІЙНЕ КОНЦЕНТРУВАННЯ ТА ВИЗНАЧЕННЯ СТИБІЮ І ТЕЛУРУ НА МОДИФІКОВАНОМУ СИЛІКАГЕЛІ}

Статтю присвячено розробці твердофазного реагенту на основі іммобілізованого на силікагелі ЧАС-тринонілоктадеииламонію хлориду і створенню на його основі сорбційно-спектроскопічних та візуальних тест-методик визначення Sb(III) та Te(IV). Досліджено взаємодію аніонних йодидних комплексів стибію та телуру з іммобілізованою на силікагелі ЧАC. Установлено, що вона відбувається за іон-асоціативним механізмом. Оптимізовано умови сорбційного вилучення аніонних комплексів металів. Вивчено вплив сторонніх іонів на ступінь вилучення досліджуваних елементів і величину аналітичного сигналу, запропоновано способи його усунення. На підставі проведених досліджень розроблено сорбційно-спектроскопічні та візуальні тест-методики визначення Sb(III) і Te(IV) у лікарських гомеопатичних препаратах.

Ключові слова: твердофазні реагенти, іммобілізація, іонні асоціати, стибій(III), телур(IV).

Вступ. Стибій та його сполуки широко використовуються в промисловості, що робить його одним із пріоритетних забруднювачів повітря та водного середовища. Переважно використовується у вигляді свинцевих та олов'яних сплавів для акумуляторних пластин, кабельних оболонок, підшипників, поліграфрічних сплавів, застосовується при виробництві діодів, інфррачервоних детекторів. У медичній практиці ліки, що містять стибій, використовують як протипротозойні засоби. Надлишок стибію вибірково концентрується в щитовидній залозі, печінці, селезінці. Стибій і його сполуки отруйні. Проявом токсичної дії стибію є різноманітні порушення функцій людського організму [1-3].

В Україні офріційних обмежень на вміст стибію у водах різних категорій немає. Однак ВООЗ нормує вміст даного елемента у питних водах на рівні 5 мкг/л [4]. У деяких країнах також установлено гранично допустимі норми стибію в продуктах харчування, зокрема напоях (соках). Особливо небезпечним джерелом стибію $є$ емальований посуд, 3 якого він легко вилучається кислотами.

Одним 3 найбільш поширених методів визначення стибію залишається простий у виконанні фоотометричний йодидний метод $[5,6]$. Головною його вадою $є$ недостатня чутливість, на відміну від інших фотометричних методів визначення стибію, що ґрунтуються на екстракції іонних асоціатів із основними барвниками чи утворенні відновлених гетерополікислот (ГПК) [5-7]. Вони високочутливі та селективні, але водночас трудомісткі та мають низьку відтворюваність результатів аналізу.

У літературі нами не знайдено інформації щодо тестових систем для визначення стибію.

Останнім часом телур все частіше стає предметом дослідження хіміків-аналітиків. Телур - біологічно активний елемент, його концентрація в навколишньому середовищі суворо регламентується. Відповідно до санітарних правил і норм гранично допустима концентрація телуру в питній воді становить 0,01 мг/л [4]

Більшість спектрофоотометричних методів (СФ) визначення телуру ґрунтуються на використанні забарвлених, переважно жовтих, комплексів телуру(IV) 3 органічними та неорганічними реагентами $[5,8,9]$. Для визначення телуру часто застосовують тіосечовинний метод, екстракційно-фотометричний метод з використанням вісмутіолу II. Серед тестових методів було запропоновано метод визначення телуру(IV), що базується на його реакції з вісмутіолом II, іммобілізованим на папері, а також малахітовим зеленим, іммобілізованим на віскозній тканині, як реагентом для швидкого визначення телуру(IV) за інтенсивністю забарвлення іонного асоціату реагенту з телуромолібденовою ГПК [10].

Однак найбільш поширеним методом визначення телуру залишається фоотометричний йодидний метод $[5,8$, 9]. Головний недолік - недостатня чутливість, на відміну від інших фоотометричних методів визначення телуру.

Створення комбінованих методів аналізу на основі твердофазних аналітичних реагентів стало перспективним напрямом сучасної аналітичної хімії. Переваги таких методів загальновідомі. За рахунок простого адсорбційного закріплення четвертинних амонієвих солей (ЧАС) силікагелі (СГ) набувають властивостей аніоніту, що дозволяє поєднувати операції концентрування та детектування безпосередньо у фазі концентрату. Сорбція забарвлених сполук на модифікованих носіях відкриває нові можливості для створення комбінованих спектрометричних методик і тест-систем для експрес-аналізу [11-16].

Метою даної роботи було вивчення взаємодії стибію(III) та телуру(IV) у формі йодидних комплексів з іммобілізованою на силікагелі ЧАС - хлоридом тринонілоктадециламонію (ТНОДА), розробка сорбційно-спектроскопічних і візуально-тестових методик визначення даних металів та їх апробація на реальних об'єктах.

Матеріали і методи дослідження. У роботі використовували ЧАС-СГ, отриманий адсорбційною модифікацією силікагелю ТНОДА [17], ємність сорбенту становить 0,12 ммоль/г. Воду очищали згідно з рекомендаціями [18]. Сорбент послідовно промивали насиченим розчином $\mathrm{NaCl}$ у присутності $\mathrm{Na}_{2} \mathrm{~S}_{2} \mathrm{O}_{3}$ і бідистильованою водою до негативної реакції на хлорид. Сушили на повітрі, а потім у сушильній шафрі за температури $353 \pm 1 \mathrm{~K}$. Стандартний розчин телуру(IV) готували розчиненням наважки елементного телуру в концентрованій нітратній кислоті у присутності хлоридної кислоти. Використовували $\mathrm{K}(\mathrm{SbO}) \mathrm{C}_{4} \mathrm{H}_{4} \mathrm{O}_{6} \cdot 0,5 \mathrm{H}_{2} \mathrm{O}$ (х.ч.), $\mathrm{KI}$ (ос.ч.), $\mathrm{H}_{2} \mathrm{SO}_{4}$ (х.ч.), $\mathrm{HCl}$ (х.ч.), аскорбінову кислоту (х.ч.), сечовину (ос.ч.) [19]. Вихідні розчини реагентів готували за наважкою 